\title{
Growth hormone treatment after renal transplantation: a promising but underused chance to improve growth
}

\author{
Otto Mehls • Richard N. Fine
}

Received: 3 August 2012 / Accepted: 6 August 2012 /Published online: 5 September 2012

(C) IPNA 2012

\begin{abstract}
Growth retardation remains a clinical problem in children with chronic kidney disease (CKD) prior to and during end-stage renal disease. The growth of approximately $40 \%$ of children on dialysis is stunted. Even so, growth hormone treatment $(\mathrm{GH})$ is not used in the majority of small children prior to transplantation. Also, $\mathrm{GH}$ is effective in improving growth after transplantation, but again, it is only rarely used in this situation mainly for fear of triggering rejection episodes. In controlled studies, the number of patients who developed rejection episodes with GH was no greater than the number in untreated controls. However, patients with prior frequent rejection episodes developed further repeated subsequent rejection episodes. Many patients with repeated rejection episodes before GH treatment have reduced renal function and are expected to proceed to dialysis or retransplantation. We believe that in these patients, early individual decisions for or against GH treatment should be made as soon as other treatment strategies, such as steroid withdrawal, have failed or are not indicated. Decisions for GH treatment at a later pubertal age come too late for significant growth response and/or improvement of final height.
\end{abstract}

Keywords Growth hormone · Renal transplant · Chronic kidney disease $\cdot$ End stage renal disease

\section{Introduction}

Cheng et al. publish in this issue a meta-analysis on growth hormone $(\mathrm{GH})$ treatment in short children with renal

O. Mehls $(\bowtie)$

Centrum for Children and Adolescents, University Hospitals,

Heidelberg, Germany

e-mail: Otto.Mehls@med.uni-heidelberg.de

R. N. Fine

Department of Pediatrics, Stony Brook Medicine,

Stony Brook, NY, USA transplantation (TPL) [1]. The authors conclude and confirm that GH treatment is highly effective in improving growth, but safety "needs further evaluation." The latter statement deserves comment. Fear of rejection episodes has prevented regular use of GH in transplanted children during the last two decades. At the same time, steroid withdrawal [2] or even steroid-free immunosuppression [3] became a popular new strategy to improve growth after TPL. This raises the question of whether GH treatment is needed at all in transplanted children. We believe that there are still many patients who can benefit from GH treatment.

Growth before end-stage renal disease

In general, conservative treatment in children with chronic kidney disease (CKD) has improved greatly over recent decades. Proper nutrition is now recognized as an important precondition to prevent chronic kidney disease-bone and mineral disorder (CKD-BMD). It has been claimed frequently that adequate nutrition will solve most growth problems [4]. Contrary to expectations, however, growth retardation and stunting persist in a significant proportion of children at time of dialysis treatment. In selected and unselected cohorts of dialyzed patients, height standard deviation score (SDS) is reported to be below the 3rd percentile or below -2 SDS in more than $40 \%$ of the children [5, 6]. Even in centers with optimal nutrition strategies, more than $40 \%$ of dialyzed patients present with a height SDS $<-2$ SD and the mean growth during dialysis only paralleled existing centiles but did not manifest catchup growth [7].

Tube feeding and adequate protein/calorie intake improve growth in infants and young children with CKD. However, interpolation of the early growth response until the time of final height provided a too optimistic view [8], and analysis of the same patients 10 years later showed disappointing results [9]. Despite optimal 
nutrition, growth remained suboptimal in many young patients, although they became obese [10]. The results from the International Peritoneal Dialysis Registry Study demonstrate that this is a world-wide phenomenon [11].

Two recent reports from the US analyzing height, growth, and frequency of GH treatment in children of all age groups with CKD reported that the frequency of growth retardation is still $>40 \%[12,13]$. GH treatment was used in $<50 \%$ of stunted children with CKD [14]. The authors recommended that the growth of those patients be followed more closely and that $\mathrm{GH}$ be prescribed earlier and more frequently.

Growth and final height at renal transplantation

Analysis of North American Pediatric Renal Trials and Collaborative Studies (NAPRTCS) data in 2006 showed a mean height SDS of -1.5 at the time of renal transplantation [14]. These somewhat better growth data in comparison with children on dialysis, as reported above, might be explained by different age groups and by patients undergoing preemptive transplantation for which the NAPRTCS data were not corrected. Only children up to 5 years old exhibited catch-up growth mainly during the first 2 years posttransplantation. In various single-center studies published between 2000 and 2011, the frequency of final height SDS $<-2$ SD varied between $32 \%$ and $77 \%$ [15-19]. Even today, the clinical problem of stunting seems to be greater than is anticipated by the community.

\section{Growth after steroid avoidance for renal transplantation}

Complete avoidance [3] or selective withdrawal [2] of corticosteroids leads without doubt to significant improvement in growth. This is reported especially for young children, who are known to have the best growth rates even with corticosteroid-based treatment regiments. In the multicenter study of Sarwal et al. [3], the subgroup of recipients $<5$ years of age showed improvement in height SDS $(1.07 \pm 1.14$ within 3 years $)$ with complete avoidance of corticosteroids when compared with patients on steroid-based treatment $(0.43 \pm 1.15)$. Late selective withdrawal of corticosteroids in the randomized study of Höcker et al. [2] improved height SDS by $+0.6 \pm 0.1$ within 2 years compared with $-0.2 \pm 0.1$ in controls. In both reported studies, as in most others, negative effects regarding rejection episodes and renal function were noted only rarely. One must keep in mind that so far, growth and renal function were observed only in the short to medium term. In most steroid withdrawal studies, the immunosuppressive regiments compensate for steroid withdrawal by increasing target levels of calcineurin inhibitors or by adding other drugs (for instance, antibodies such as daclizumab) [3]. Future long-term studies must show whether or not renal function is negatively influenced by the new immunosuppressive regiments. This is expected at least for high levels of calcineurin inhibitors. It is further expected that the growth effect of steroid avoidance will decrease with age.

Growth hormone treatment after renal transplantation

The meta-analysis by Cheng et al. [1] and the Cochrane Review analysis from February 2012 [20] confirmed the effectiveness of GH treatment after TPL in short children. However, many physicians believe that adverse events regarding rejection episodes are relevant. Is this assumption correct? The sparse preliminary experimental data on immunomodulation by GH mentioned by Cheng et al. [1] may addresses this issue but does not allow us to draw any clinical conclusions.

The first large randomized clinical study from France involving 90 short children after TPL did not show a significant difference between study and control patients [21]. The number of patients with rejection episodes in both groups was not significantly different. However, patients with two and more rejection episodes before the start of the study had more frequent rejection episodes when treated with GH (6 of 17 vs 1 of 22). This difference was significant. The French study was part of a larger multicentre, multicountry study in which 204 patients were enrolled and followed for 2 years. The responsible sponsor decided not to publish the 1- and 2-year results of the complete study because of violations of the protocol (early start of study in some centers). The unpublished 1- and 2-year results were similar to the published French results [22]. Deterioration of renal function was not negatively influenced by GH treatment. Also, the number of patients with rejection episodes was not significantly different between $\mathrm{GH}$ and control patients. In contrast, patients with prior frequent rejection episodes were reported to have more rejection episodes with GH. However, the study was not designed to study $\mathrm{GH}$ effect for acute rejection episodes but to assess the $\mathrm{GH}$ effect on renal function. "Acute rejection episode" was not defined in the protocol, and data started to be collected 2 years after study initiation. One major limitation was the missing confirmation of rejection episodes by renal biopsy in about $50 \%$ of patients and controls. It is likely that an increase in serum creatinine level during the test phase of an investigational drug was assumed to be a rejection episode by the responsible physician. Without doubt, it was more tempting to perform such clinical interpretation in the treatment group.

In the small controlled study of Maxwell and Rees, the presumed number of acute rejection episodes was not different 
between GH and control groups [23]. The only randomized study with protocol biopsies prior to randomization and strict confirmation of rejection by repeated biopsies was performed in the USA in 68 patients over a period of 2 years [24]. All patients had a renal biopsy at trial initiation, and all clinical rejection episodes had to be confirmed by biopsy. Two important results were obtained: First, three patients unexpectedly showed histological signs of rejection prior to study initiation, demonstrating how difficult the clinical identification of a stable patient can be. Second, in the control group only, three de novo rejection episodes were confirmed by biopsy during the first study year, whereas no rejection was noted in the treatment group. Nota bene, the total incidence of acute rejection episodes was low in comparison with other published studies. The study also confirmed that patients with two or more rejection episodes in the past were predisposed to repeated rejection episodes. Therefore, more than one acute rejection episode may identify a patient population that is suboptimally immunosuppressed or more immunoreactive. However, data did not facilitate identification of GH treatment as precipitating an acute rejection episode.

It is not likely that new prospective randomized studies will be performed in the future. Therefore, we must live with the data we have. It has not been proven that GH treatment triggers rejection episodes in stable patients. Similarly, no study demonstrating GH-triggered rejection episodes has been published for short children after liver transplantation [25]. Renal patients who respond to steroid avoidance and grow well do not require GH treatment. But how should we proceed in nongrowing, short, transplanted patients? Patients with chronic rejection or repeated rejection episodes are at risk of new episodes with or without GH treatment. An increased risk with GH is not proven but cannot be ruled out, either. If there is a risk at all, it will be small.

Is GH treatment therefore contraindicated in those patients? We do not support this type of reasoning. Patients with frequent rejection episodes and decreased renal function do not show satisfactory growth and often receive glucocorticoids. In addition, many of those patients are peripubertal and at great risk of attaining subnormal final height. In those patients, both treating physicians and patients' families should make an early and clear decision for or against GH treatment. If necessary, this should be done with the help of specialists.

We are aware that neither in the USA nor in Europe is $\mathrm{GH}$ approved for treatment of growth failure after transplantation. In Germany, insurance companies usually pay for the treatment if the patient has a reduced glomerular filtration rate (GFR) of $50 \%$ of normal. The American Association of Clinical Endocrinology did not recommend the use of GH in transplanted patients outside research studies [26]. In contrast, The National Kidney Foundation Kidney Disease Outcomes Quality Initiative (K/DOQI) guidelines do not exclude small transplanted patients from treatment if renal function is impaired [27]. Until alternative promising treatment strategy has been found, individual decisions seem justified. A "wait and see" approach is not a recommendable strategy. Early GH treatment has higher chances of success than treatment attempts at the last moment. The initial degree of stunting and of bone-age retardation, GH therapy duration, time spent on conservative treatment/dialysis, pubertal delay $(>2 \mathrm{SD})$, gender, and age at start of GH treatment are independent predictors of growth response to $\mathrm{GH}$ therapy, explaining $>50 \%$ of the overall variability [28].

\section{Conclusion}

Growth hormone remains one alternative treatment strategy for small children after renal transplantation. It is safe, and it can be prescribed in individual patients if steroid avoidance is not successful. Minor and infrequent growth response to steroid avoidance is expected mainly in older patients who, however, represent the majority of transplanted patients in the pediatric population.

\section{References}

1. Wu Y, Cheng W, Yang XD, Xiang B (2012) Growth hormone improves growth in pediatric renal transplant recipients-a systemic review and meta-analysis of randomized controlled trials. Pediatr Nephrol. doi:10.1007/s00467-012-2208-7

2. Sarwal MM, Ettenger R, Dharnidharka V, Benfield M, Mathias R, Portale A, McDonald R, Harmon W, Kershaw D, Vehaskari VM, Kamil E, Baluarte HJ, Warady B, Tang L, Liu J, Li L, Naesens M, Sigdel T, Waskerwitz J, Salvatierra O (2012) Complete Steroid Avoidance Is Effective and Safe in Children With Renal Transplants: a Multicenter Randomized Trial with Three-Year FollowUp. Am J Transplant. doi:10.1111/j.1600-6143.2012.04145.x

3. Höcker B, Weber LT, Feneberg R, Drube J, John U, Fehrenbach H, Pohl M, Zimmering M, Fründ S, Klaus G, Wühl E, Tönshoff B (2010) Improved growth and cardiovascular risk after late steroid withdrawal: 2-year results of a prospective, randomised trial in paediatric renal transplantation. Nephrol Dial Transplant 25 (2):617-624

4. Ledermann SE, Spitz L, Moloney J, Rees L, Trompeter RS (2002) Gastrostomy feeding in infants and children on peritoneal dialysis. Pediatr Nephrol 17(4):246-250

5. Fischbach M, Fothergill H, Seuge L, Zaloszyc A (2011) Dialysis strategies to improve growth in children with chronic kidney disease. J Ren Nutr 21(1):43-46, Review

6. Lewis M, Shaw J, Reid C, Evans J, Webb N, Verrier-Jones K (2007) Growth in children with established renal failure-a Registry analysis (chapter 14). Nephrol Dial Transplant 22(Suppl 7): vii176-vii180

7. Cansick J, Waller S, Ridout D, Rees L (2007) Growth and PTH in prepubertal children on long-term dialysis. Pediatr Nephrol 22 (9):1349-1354

8. Kari JA, Gonzalez C, Ledermann SE, Shaw V, Rees L (2000) Outcome and growth of infants with severe chronic renal failure. Kidney Int 57(4):1681-1687 
9. Mekahli D, Shaw V, Ledermann SE, Rees L (2010) Long-term outcome of infants with severe chronic kidney disease. Clin J Am Soc Nephrol 5(1):10-17

10. Coleman JE, Watson AR, Rance CH, Moore E (1998) Gastrostomy buttons for nutritional support on chronic dialysis. Nephrol Dial Transplant 13(8):2041-2046

11. Rees L, Azocar M, Borzych D, Watson AR, Büscher A, Edefonti A, Bilge I, Askenazi D, Leozappa G, Gonzales C, van Hoeck K, Secker D, Zurowska A, Rönnholm K, Bouts AH, Stewart H, Ariceta G, Ranchin B, Warady BA, Schaefer F, International Pediatric Peritoneal Dialysis Network (IPPN) registry (2011) Growth in very young children undergoing chronic peritoneal dialysis. J Am Soc Nephrol 22(12):23032312

12. Mahan JD, Warady BA, Consensus Committee (2006) Assessment and treatment of short stature in pediatric patients with chronic kidney disease: a consensus statement. Pediatr Nephrol 21(7):917930

13. Greenbaum LA, Hidalgo G, Chand D, Chiang M, Dell K, Kump T, Peschansky L, Smith HK, Boyle M, Kopf M, Metz LC, Kamel M, Mahan JD (2008) Obstacles to the prescribing of growth hormone in children with chronic kidney disease. Pediatr Nephrol 23 (9):1531-1535

14. North American Pediatric Renal Trials and Collaborative Studies (2006) Annual report: https:/web.emmes.com/study/ ped/annualrept2006pdf.Accessede 1 June 2007

15. Haffner D, Schaefer F, Nissel R, Wühl E, Tönshoff B, Mehls O (2000) Effect of growth hormone treatment on the adult height of children with chronic renal failure. German Study Group for Growth Hormone Treatment in Chronic Renal Failure. N Engl J Med 343(13):923-930

16. Nissel R, Brázda I, Feneberg R, Wigger M, Greiner C, Querfeld U, Haffner D (2004) Effect of renal transplantation in childhood on longitudinal growth and adult height. Kidney Int 66(2):792-800

17. Fine RN, Stablein D (2005) Long-term use of recombinant human growth hormone in pediatric allograft recipients: a report of the NAPRTCS Transplant Registry. Pediatr Nephrol 20(3):404-408

18. Vester U, Schaefer A, Kranz B, Wingen AM, Nadalin S, Paul A, Malagò M, Broelsch CE, Hoyer PF (2005) Development of growth and body mass index after pediatric renal transplantation. Pediatr Transplant 9(4):445-449

19. Tainio J, Qvist E, Vehmas R, Jahnukainen K, Hölttä T, Valta H, Jahnukainen T, Jalanko H (2011) Pubertal development is normal in adolescents after renal transplantation in childhood. Transplantation 92(4):404-409

20. Hodson EM, Willis NS, Craig JC (2012) Growth hormone for children with chronic kidney disease. Cochrane Database Syst Rev 2:CD003264, Review

21. Guest G, Bérard E, Crosnier H, Chevallier T, Rappaport R, Broyer M (1998) Effects of growth hormone in short children after renal transplantation. French Society of Pediatric Nephrology. Pediatr Nephrol 12(6):437-446

22. Johansson G, Sietnieks A, Janssens F, Proesmans W, Vanderschueren-Lodeweyckx M, Holmberg C, Sipilä I, Broyer M, Rappaport R, Albertsson-Wikland K, Berg U, Jodal U, Rees L, Rigden SPA, Preece MA (1990) Recombinant human growth hormone treatment in short children with chronic renal disease, before transplantation or with functioning renal transplants: an interim report on five European studies. Acta Paediatr Scand 79 (suppl 370):36-42

23. Maxwell H, Rees L (1998) Randomised controlled trial of recombinant human growth hormone in prepubertal and pubertal renal transplant recipients. British Association for Pediatric Nephrology. Arch Dis Child 79(6):481-487

24. Fine RN, Stablein D, Cohen AH, Tejani A, Kohaut E (2002) Recombinant human growth hormone post-renal transplantation in children: a randomized controlled study of the NAPRTCS. Kidney Int 62(2):688-696

25. Puustinen L, Jalanko H, Holmberg C, Merenmies J (2005) Recombinant human growth hormone treatment after liver transplantation in childhood: the 5-year outcome. Transplantation 79(9): 1241-1246

26. Gharib H, Cook DM, Saenger PH, Bengtsson BA, Feld S, Nippoldt TB, Rodbard HW, Seibel JA, Vance ML, Zimmerman D, American Association of Clinical Endocrinologists Growth Hormone Task Force (2003) American Association of Clinical Endocrinologists medical guidelines for clinical practice for growth hormone use in adults and children-2003 update. Endocr Pract 9 (1):64-76

27. National Kidney Foundation (NFK) (2005). K/DOQI Clinical Practice Guidelines for bone metabolism and disease in children with chronic kidney disease: http://www.org/professionals/ KDOQI/guidelines_pedbone/guide11.htm. Assesed June 12007

28. Nissel R, Lindberg A, Mehls O, Haffner D, Pfizer International Growth Database (KIGS) International Board (2008) Factors predicting the near-final height in growth hormone-treated children and adolescents with chronic kidney disease. J Clin Endocrinol Metab 93(4):1359-1365 